

\title{
Monte Carlo Simulations for a Preliminary Design of TRIGA IPR-R1 PGAA Facility
}

Bruno Teixeira Guerra ${ }^{1,2}$, Alexandre Soares Leal ${ }^{2}$, Claubia Pereira ${ }^{1}$ and Maria Angela de Barros Correia Menezes ${ }^{1,2}$

1. DEN (Departamento de Engenharia Nuclear), UFMG (Universidade Federal de Minas Gerais), Av. Antonio Carlos 6627, Campus Pampulha, CEP 31270 901, Belo Horizonte, Minas Gerais, Brazil

2. CDTN (Nuclear Technology Development Center), CNEN (Brazilian Commission for Nuclear Energy), Av. Antonio Carlos 6627, Campus UFMG, CEP 31270 901, Belo Horizonte, Minas Gerais, Brazil

\begin{abstract}
In this paper, the evaluation of a preliminary design of a PGAA (prompt gamma activation analysis) facility based on Monte Carlo simulations is presented and discussed. The implementation of the PGAA method at the CDTN (nuclear technology development centre) would increase the applications of the TRIGA reactor. The preliminary design is based on a quasi vertical hollow cylinder (called neutron extractor) in the reactor pool to extract the neutron flux. This study evaluates the neutron flux in the upper position of the cylinder in the suggested position of the samples to be analyzed by the PGAA. The calculations of the radioactive capture reaction rates and of the detection limits for some isotopes were performed. Through all these calculations, the feasibility of the application of the PGAA method at the IPR-R1 installations was evaluated. According to the obtained results, it can be concluded that is possible to apply the PGAA method at the IPR-R1 reactor, even with its design restrictions.
\end{abstract}

Key words: PGAA facility, neutron activation analysis, TRIGA IPR-R1, PGAA, NAA.

\section{Introduction}

Research nuclear reactors have been used as a tool of production of radionuclides for several studies in radiobiology, nuclear medicine [1], environment, as well as in analytical chemistry, performing the neutron activation technique, NAA (neutron activation analysis) [2].

NAA is based on the properties of radionuclides produced during the irradiation to determine the elemental concentration in samples of various matrices through the spectra of the gamma rays emitted. When the gamma rays are detected during the neutron irradiation, NAA is called PGAA (prompt gamma activation analysis). The PGNAA is based on prompt-gamma rays produced by neutron capture reactions within the sample elements and they are detected by appropriate gamma-ray spectrometry

Corresponding author: Claubia Pereira, professor, $\mathrm{PhD}$, research field: nuclear engineering. systems [3]. Several types of neutron sources (reactors, particle accelerators, natural sources) can be used to carry out the NAA. However, the application using nuclear reactors accounts over $90 \%$ of all applications of this technique [4].

The TRIGA IPR-R1 nuclear reactor, at CDTN, has operating since 1960 [5]. Since then, the Laboratory for Neutron Activation Analysis has been working analyzing several kinds of samples. Since 2000, the $k_{0}$-INAA method has been applied $[6,7]$.

In 2001, a program to optimize the use of the TRIGA was initiated and several projects started to be developed, such as the investigation of the mechanisms for the improvement of Brazilian gems and production of radioisotopes for new radiopharmaceuticals studies [8, 9]. Despite the advantages over other analytical techniques, the NAA cannot be used to determine the concentration of some elements like $\mathrm{H}, \mathrm{B}, \mathrm{C}, \mathrm{Si}, \mathrm{Pb}$ and others, due to their nuclear properties. 
In this scenario, the establishment of PGAA at CDTN would be a possibility to expand not only the use of the TRIGA reactor, but also the NAA. Besides, PGAA is a rapid, non-destructive and powerful multi-elemental analysis technique $[3,10,11]$.

The laboratories around the world that apply the PGAA method using a nuclear reactor as a neutron source, in general have a structural design that allows the extraction of the neutron flux horizontally [12]. As the IPR-R1 reactor is located inside a pool, the extraction of the neutron flux cannot be performed in the same manner (horizontally). Therefore, it would be necessary to insert an inclined hollow cylinder to extract the neutrons from the reactor's core, Fig. 1. Moreover, this cylinder should be inclined in a way that it would reach the heavy structure of the rack containing the shielding, the sample and the detector located directly over the reactor's pool, for security reasons [12-14]. This is the main difficulty to extract a neutron beam from the TRIGA IPR-R1 reactor.

Thus, the aim of this study was to evaluate theoretically if the neutron flux in the projected position of the sample would allow carrying on PGAA measurements.

According to the literature $[3,10]$, the lower neutron flux found to PGAA application at the installations using nuclear reactors as a neutron source, is approximately $10^{5} \mathrm{ncm}^{-2} \cdot \mathrm{s}^{-1}$. The extraction of the neutron flux in the reactor pool has aimed the induction of the radioactive capture reaction in the sample (considering the TRIGA neutron flux characteristics, it is expected that this is the main reaction to the PGAA application).

The isotopes chosen for the calculations applying MCNP were ${ }^{1} \mathrm{H},{ }^{28} \mathrm{Si}$, and ${ }^{58} \mathrm{Ni}$, isotopes with highest isotopic abundance related to their elements, $\mathrm{H}, \mathrm{Si}$, and $\mathrm{Ni}$, respectively. Besides, these elements $(\mathrm{H}, \mathrm{Ni}$ and $\mathrm{Si}$ ) are not analyzed by conventional NAA due to their nuclear characteristics. Their determinations are relevant because they have a large variety of applications in many different areas, such as building materials, fossil fuels, nuclear, agriculture, medicine, among others $[3,8]$.

Along the years, the TRIGA IPR-R1 reactor has been studied and modeled using the MCNP (Monte Carlo N-Particle) code. Several studies using the MCNP code have developed theoretical methods to calculate neutron flux in the sample's irradiation devices of the IPR-R1 reactor (central thimble, rotary rack, and two pneumatic tubes) and compare their results with experimental data in order to validate these models [15-17].

The model developed in this paper is based on these already validated models and on a MCNP5 model validated by this research in a previous study of the neutron flux in the vertical extractor [12]. Thus, the neutron flux behavior along the angled extractor was calculated as well as the neutron flux; capture reaction rate and detection limits along the samples of the selected isotopes.

In order to verify the viability to apply the PGAA to determine $\mathrm{H}, \mathrm{Si}$ and $\mathrm{Ni}$, this study was carried on. This approach took the advantage to generate the required data giving support to take a future decision to install a proposed PGAA facility at CDTN.

\section{Methodology}

\subsection{Geometry of the PGAA Setup}

Figs. 1 and 2 show the scheme of the neutron extractor inside of the reactor pool and Fig. 3, the location of the proposed PGAA facility-sample irradiation position and gamma spectrometry system-nearby the upper extremity of the neutron extractor.

To set up a preliminary model of the PGAA method at the IPR-R1 reactor and estimate the calculations at PGAA facility, in this work was used the models of previous studies [12, 15-17] that were validated through the MCNP5 code.

The main parameters configured for the study of PGAA application were, Fig. 4:

- Inclined neutron extractor: aluminium layer of 
$0.2 \mathrm{~cm}$ thick, inner radius of $4.8 \mathrm{~cm}$; outer radius of

$5.0 \mathrm{~cm}$ and length $850.0 \mathrm{~cm}$; angle 10 degrees;

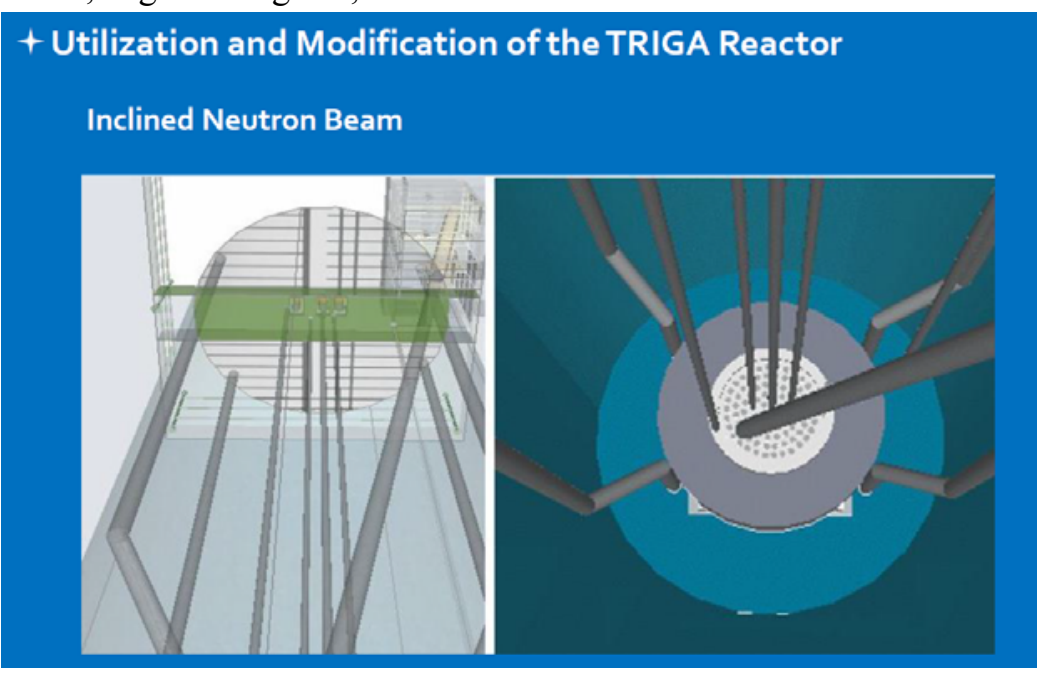

Fig. 1 View of the IPR-R1 reactor pool with the angled neutron extractor.

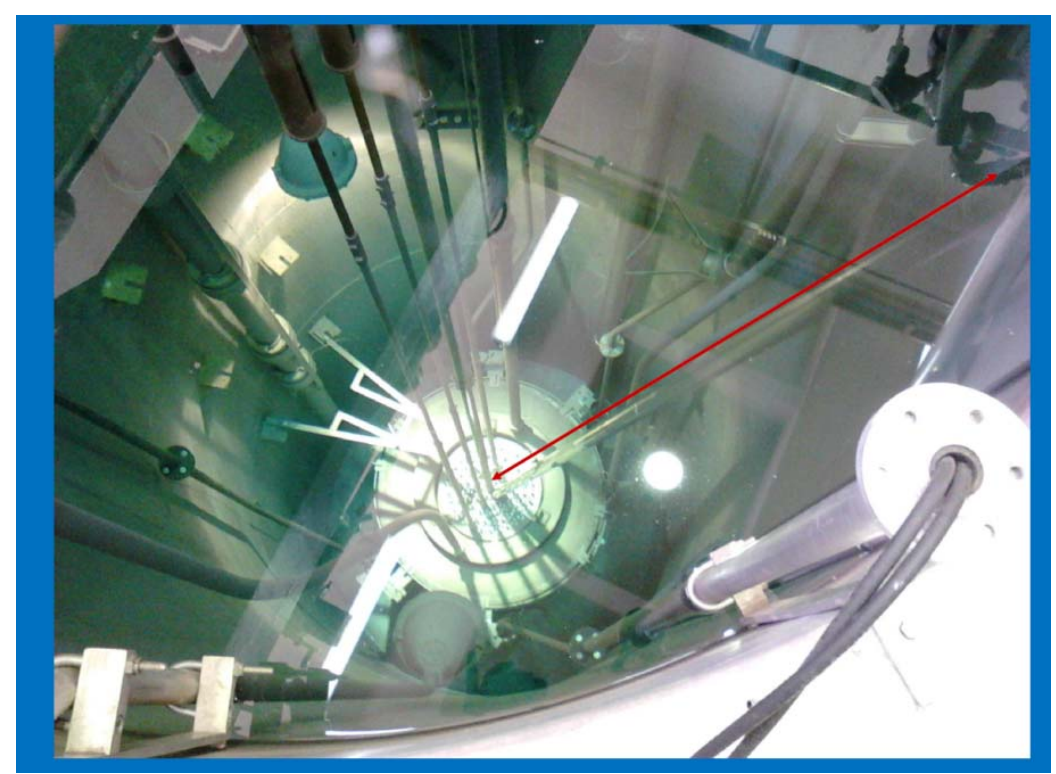

Fig. 2 Axial view of the IPR-R1 reactor pool with the angled neutron extractor.

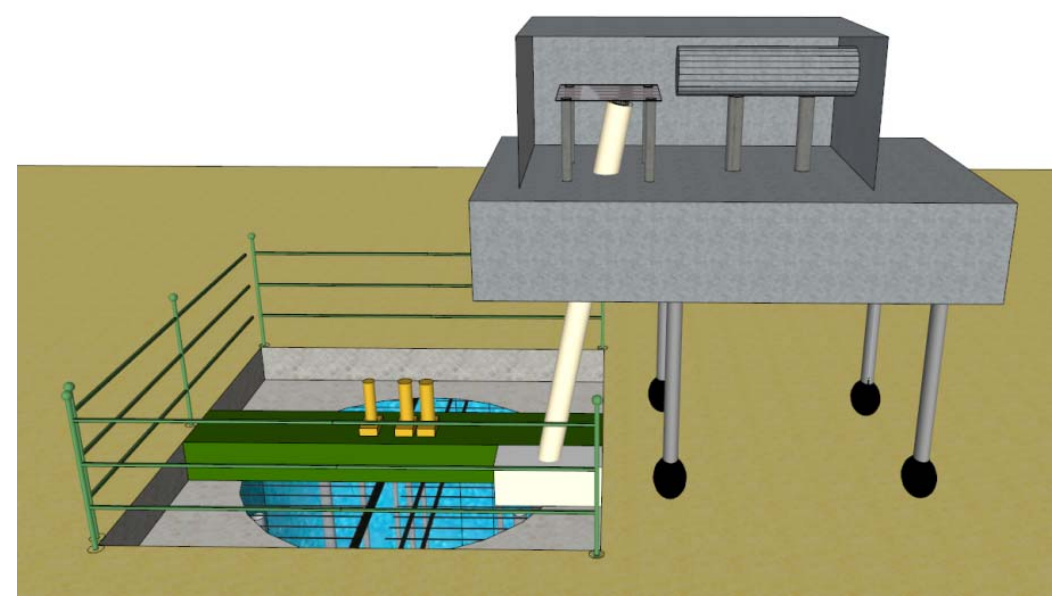


Fig. 3 View of the IPR-R1 reactor pool and the proposed PGAA facility-sample irradiation position and gamma spectrometry system.

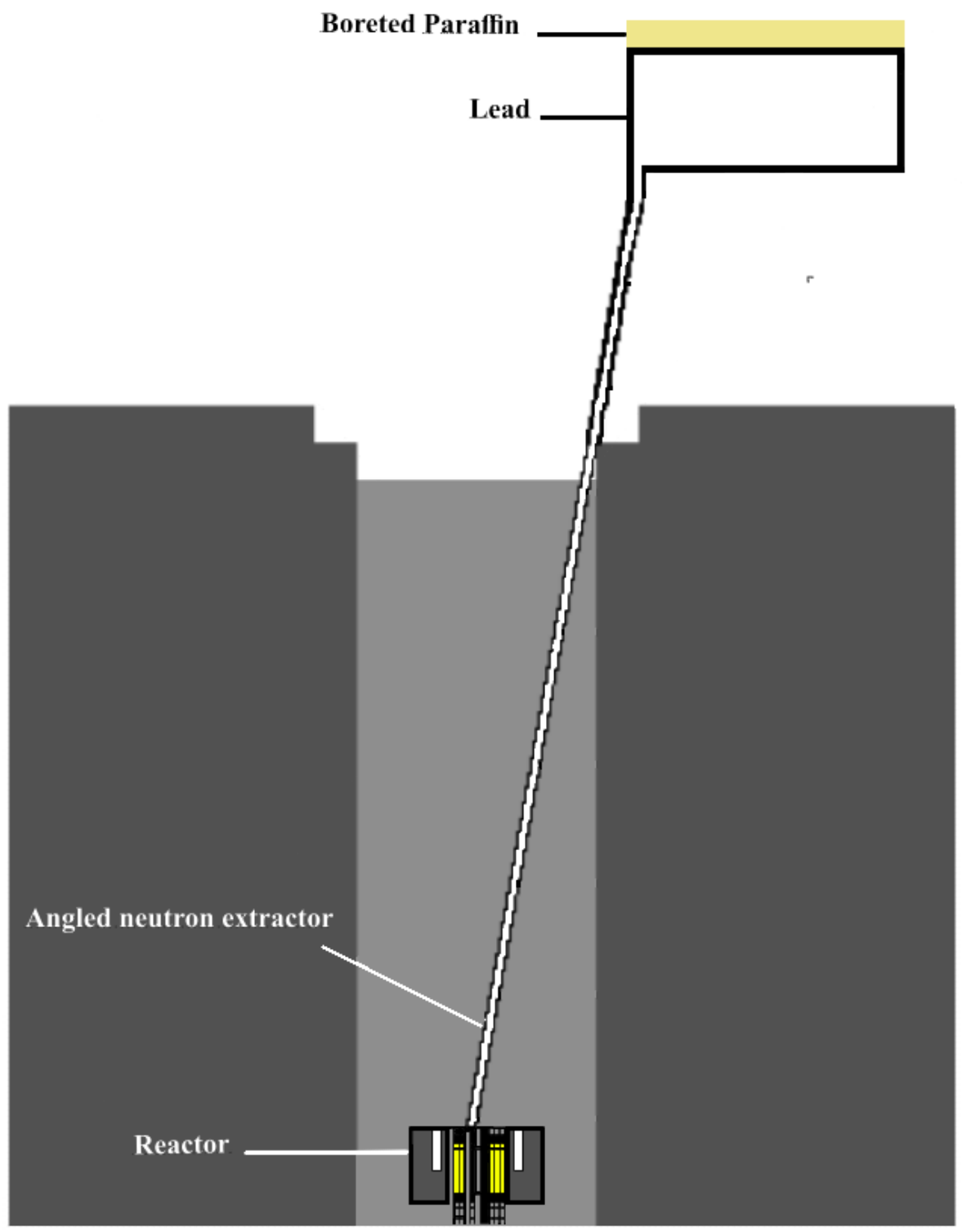

Fig. 4 Proposed PGAA facility, designed by MCNP5.

- Irradiation chamber: lead layer with $5 \mathrm{~cm}$ thick, it was configured with $50 \mathrm{~cm}$ of length and depth surrounding an air chamber;

- Borated paraffin shield: $20 \mathrm{~cm}$ thick covering the entire upper surface of the irradiation chamber.

The inclined neutron extractor was configured with this thickness because the reactor has already a certified hollow aluminium cylinder with this dimension. Its length was planned to reach the position where the sample will be subjected to the neutron flux.

The sample is located approximately $820 \mathrm{~cm}$ from the reactor and $280 \mathrm{~cm}$ above the room floor, position idealized to apply the PGAA method. The position chosen to place the sample to be analyzed was due to the location with the higher possible neutron flux for PGAA application without installing the detection system on the reactor pool. Around the sample was configured a lead shield (called irradiation chamber) and upon this lead layer was placed a borated paraffin 
shield, in order to decrease undesired gamma rays and neutrons at the PGAA application. The thickness of the irradiation chamber was chosen based on the literature data [3]. The paraffin shielding was chosen with an excessive volume, in order to shield totally the neutron flux that crosses the upper coating of the irradiation chamber.

The dose in the reactor room with the installation of PGAA was calculated in a previous study [13]. It showed that with PGAA installation would not have increased the significant dose to allow operators working in the room where the reactor is located.

\subsection{Monte Carlo Calculations}

All calculations estimated in this study through MCNP5 [15-17] were carried out with the 5.1.40 version of the code, with the cross section of the library ENDF/B-VII.0, with the following configuration of KCODE tool MCNP5: $2.0 \times 10^{3}$ active cycles with a history of $10^{4}$ neutrons per cycle. For the calculations it was used the cluster CENAPAG-MG [6, 12-14, 18].

2.2.1 Neutron Fluence Rate in the Angled Neutron Extractor

The neutron fluence rate was simulated calculating in the angled neutron extractor ( $5 \mathrm{~cm}$ diameter), in an earlier study [6]. Considering that the reactor IPR-R1 operates routinely for 8 hours, $28,000 \mathrm{~s}$, it was necessary to make the same evaluation in a neutron extractor with a larger diameter $(10 \mathrm{~cm})$ to increase the neutron fluence rate in order to reach better precision and lower detection limits [8].

Calculations were made to evaluate the neutron spectrum behavior in the angled neutron extractor $(10$ $\mathrm{cm}$ diameter) in 10 positions, considering the first point, the position closer to the core of the reactor and the last one, at the end of the tube. The distance between the points was $100 \mathrm{~cm}$, Fig. 5 .

2.2.2 Neutron Fluence Rate, Reaction Rate, and Detection Limits in the Sample

After the study of the neutron flux throughout the inclined neutron extractor, it was calculated the neutron flux, the reaction rate and the detection limit of the chosen isotopes in the sample. For the calculations, the sample was placed in the irradiation position in the simulated PGAA facility. The isotopes chosen for these calculations are: ${ }^{1} \mathrm{H},{ }^{28} \mathrm{Si}$, and ${ }^{58} \mathrm{Ni}$. Moreover, they were chosen because they are light elements with higher capture cross section for thermal neutrons, Fig. 6 . The neutron flux through the sample has an energy spectrum more thermalized due to sample position is too far from the reactor.

The MCNP5 estimates the neutron fluence then it is necessary to normalize it as neutron fluence rate. This normalization is performed using the Eq. (1) [15-17]:

$$
\phi=\Phi_{\mathrm{MCNP}} \cdot \frac{\mathrm{P} \cdot \mathrm{v}}{\mathrm{Q} \cdot \mathrm{k}_{\mathrm{eff}}}
$$

where, $\Phi$ is the neutron fluence rate; $\Phi_{\mathrm{MCNP}}$ is the fluence estimated by MCNP5; $\mathrm{P}$ is the reactor power level; $v$ is the average number of fission neutrons; and $\mathrm{Q}$ is the recoverable energy per fission event. The MCNP5 calculates the values of $v, Q$ and $K_{\text {eff }}$ and they can be obtained in the output file.

Using the example given by MOLNAR [3], which provides a $600 \mathrm{~A}_{\min }, 0.001 \varepsilon_{\text {geom }}$ and including it in the calculated reaction rate found in this work, it was possible to get the detection limit. Eq. (2) shows how it was estimated:

$$
D L=\frac{A_{\min } M}{0.6022 \sigma_{\gamma 0} \Phi_{0} \varepsilon_{\text {geom }} t_{\text {max }}}
$$

where, $D L$ is the detection limit, expressed in $\mathrm{g} ; A_{\min }$ is the minimum area of a peak necessary for the identification; $M$ is the relative atomic mass (or simply the mass number); $0.6022 \times 10^{-24}$ is the Avogadro number; $\sigma_{\gamma 0}$ is the cross section in barns; $\Phi_{0}$ is the neutron flux; $\varepsilon_{\text {geom }}$ is geometric efficiency and $t_{\max }$ is practicable longest measuring time used.

To make these calculations, a cylindrical sample was configured with $10 \mathrm{~cm}$ of diameter and $5 \mathrm{~cm}$ of thickness, which was divided into 5 equal layers. In each simulation, a particular type of isotope was used. The sample is located approximately $820 \mathrm{~cm}$ from the 
reactor and $280 \mathrm{~cm}$ above the room floor. Around the of $5 \mathrm{~cm}$ (called irradiation chamber) and upon this sample was configured a lead shield with a thickness

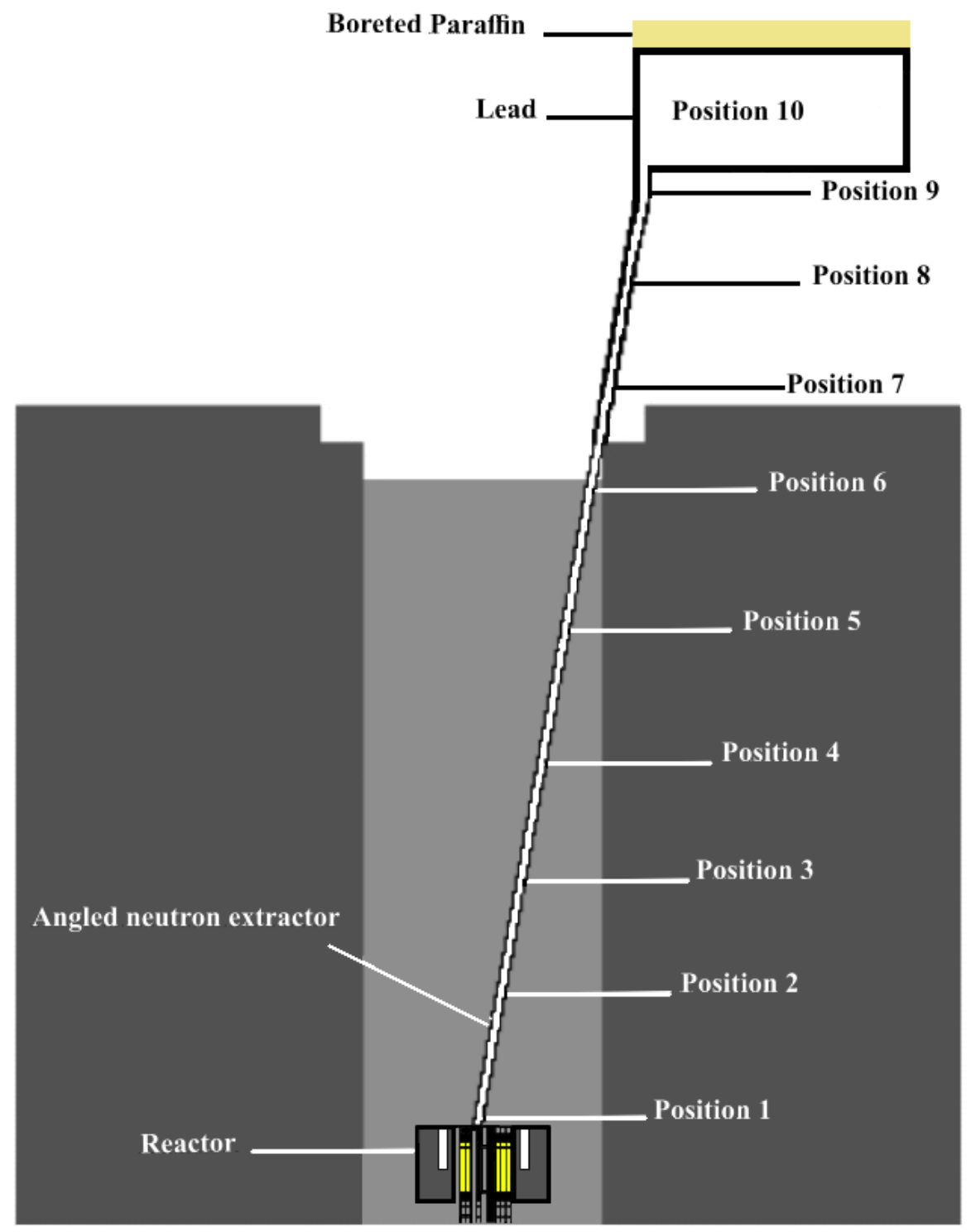

Fig. 5 Proposed PGAA facility with 10 positions along of the angled neutron extractor, designed by MCNP5.

lead layer was placed a borated paraffin shield with 20 $\mathrm{cm}$ of thickness, to simulate a more realistic PGAA system, Fig. 7.

\subsubsection{Comparison of Detection Limits}

To determine the detection limits for chosen isotopes, simulating the analysis by PGAA through TRIGA IPR-R1 reactor facilities, this study characterized 5 different Models. It was supposed that the sample was divided by layers and the detection limit estimated in the first layer of the sample at each isotope was calculated and compared them with MOLNAR [3] data as showed below:

Model 1: Standard, MOLNAR [3];

Model 2: Considering that the magnitude of the neutron flux is around $10^{8}$ in MOLNAR [3] and the TRIGA has a magnitude of approximately $10^{6}$, this Model multiplied the reaction rate by $10^{2}$. The time used followed the author example $\left(10^{5} \mathrm{~s}\right)$;

Model 3: the estimated reaction rate was multiplied by $10^{2}$, although the time used was $28,800 \mathrm{~s}$. This time 
value was used because the routine operation of the equal to $10^{5} \mathrm{~s}$; CDTN reactor is 8 hours per day.

Model 4: estimated reaction rate (MCNP5) with $\mathrm{t}$

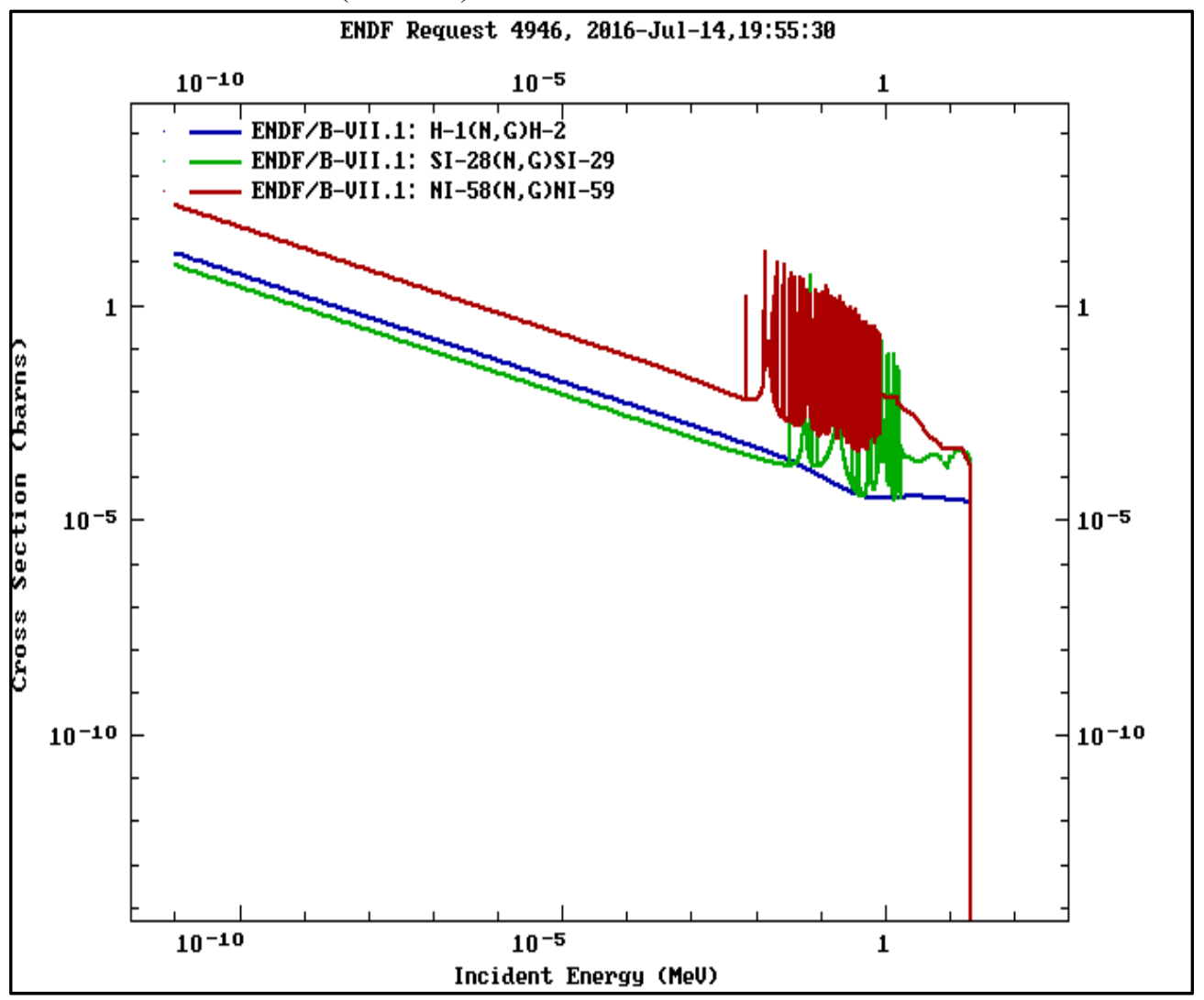

Fig. 6 Capture cross section of ${ }^{1} \mathrm{H},{ }^{28} \mathrm{Si}$ and ${ }^{58} \mathrm{Ni}[19]$.

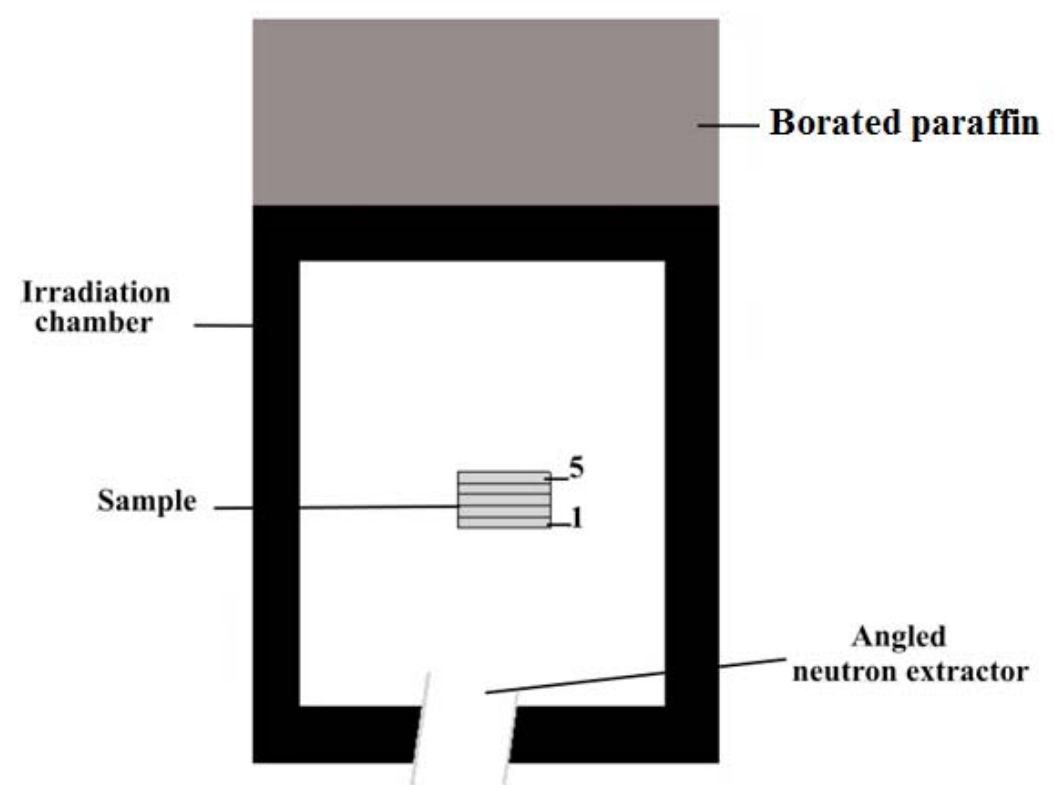

Fig. 7 Irradiation chamber of the proposed PGAA facility.

Model 5: estimated reaction rate (MCNP5) with $\mathrm{t}$ equal to 28,800 s. 
From these Models, it was possible to get results in order to make a comparison between the values obtained in this study with the experimental data obtained by MOLNAR [3].

\section{Results}

\subsection{Neutron Fluence Rate}

The neutron fluence rate was estimated in 10 positions along the angled neutron extractor, with a distance of approximately $100 \mathrm{~cm}$ between each position. The behavior of the neutron flux in each position is illustrated Fig. 8: the lower curve corresponds to position 10 and the higher curve, position 1.

As can be noted, increasing the distance of the reactor core does decrease the neutron flux but keeping the same behavior.

In the position chosen to insert the sample into the PGAA facility, a thermal neutron flux of $5.97 \times 10^{5}$ $\mathrm{ncm}^{-2} \cdot \mathrm{s}^{-1}$ and a total neutron flux of $1.13 \times 10^{6}$ $\mathrm{ncm}^{-2} \cdot \mathrm{s}^{-1}$ have been determined.

According to MCNP manual [15-17], a relative error $<10 \%$ is acceptable. For all neutron fluence rates estimated by MCNP5, the relative errors were below $10 \%$.

3.2 Neutron Fluence Rate, Reaction Rate, and Detection Limit in the Sample

The neutron flux behavior, reaction rate and detection limit were calculated in each one of the 5 layers of the sample. Figs. 9, 10 and 11 are related to isotope ${ }^{1} \mathrm{H}$, neutron flux behavior, reaction rate and detection limit, respectively. Figs. 12, 13 and 14 are related to ${ }^{28} \mathrm{Si}$, neutron flux behavior, reaction rate and detection limit, respectively, and Figs. 15, 16 and 17 are related to ${ }^{58} \mathrm{Ni}$, neutron flux, reaction rate and detection limit, respectively. The lower curve corresponds to $5 \mathrm{~cm}$ and the higher curve, $1 \mathrm{~cm}$, Figs. 15 and 16 related to neutron flux behavior along the sample and reaction rate along the sample.

Figs. 9, 12 and 15 show the estimated neutron flux in each sample for ${ }^{1} \mathrm{H},{ }^{28} \mathrm{Si}$ and ${ }^{58} \mathrm{Ni}$. It is possible to observe that the neutron flux that irradiates the samples is more thermalized, i.e., it has more thermalized neutrons $(\mathrm{E}<0.625 \mathrm{eV})$. Also, it is possible to observe that a significant variation of the thermal neutron flux did not occur along the samples for the isotope ${ }^{1} \mathrm{H}$ (layer 1: $3.28 \times 10^{6} \mathrm{ncm}^{-2} \cdot \mathrm{s}^{-1}$ and layer 5: $8.2 \times 10^{5} \mathrm{ncm}^{-2} \cdot \mathrm{s}^{-1}$ ) and ${ }^{28} \mathrm{Si}$ (layer 1: $1.66 \times$ $10^{6} \mathrm{ncm}^{-2} \cdot \mathrm{s}^{-1}$ and layer 5: $\left.1.29 \times 10^{6} \mathrm{ncm}^{-2} \cdot \mathrm{s}^{-1}\right)$.

Related to ${ }^{58} \mathrm{Ni}$ isotope, it presented a significant variation along the layers of the sample (layer 1: 1.82 $\times 10^{6} \mathrm{ncm}^{-2} \cdot \mathrm{s}^{-1}$ and layer 5: $\left.5.36 \times 10^{4} \mathrm{ncm}^{-2} \cdot \mathrm{s}^{-1}\right)$. This variation may be caused by the higher capture cross section (probability of happening the reaction) in the ${ }^{58} \mathrm{Ni}$ isotope compared to the isotopes ${ }^{1} \mathrm{H}$ and ${ }^{28} \mathrm{Si}$, according to IAEA [19] as shown in Fig. 6.

Figs. 10, 13 and 16, show that the capture reaction rates for all isotopes ${ }^{1} \mathrm{H},{ }^{28} \mathrm{Si}$, and ${ }^{58} \mathrm{Ni}$ most occur at the thermal region. In agreement with the cross 


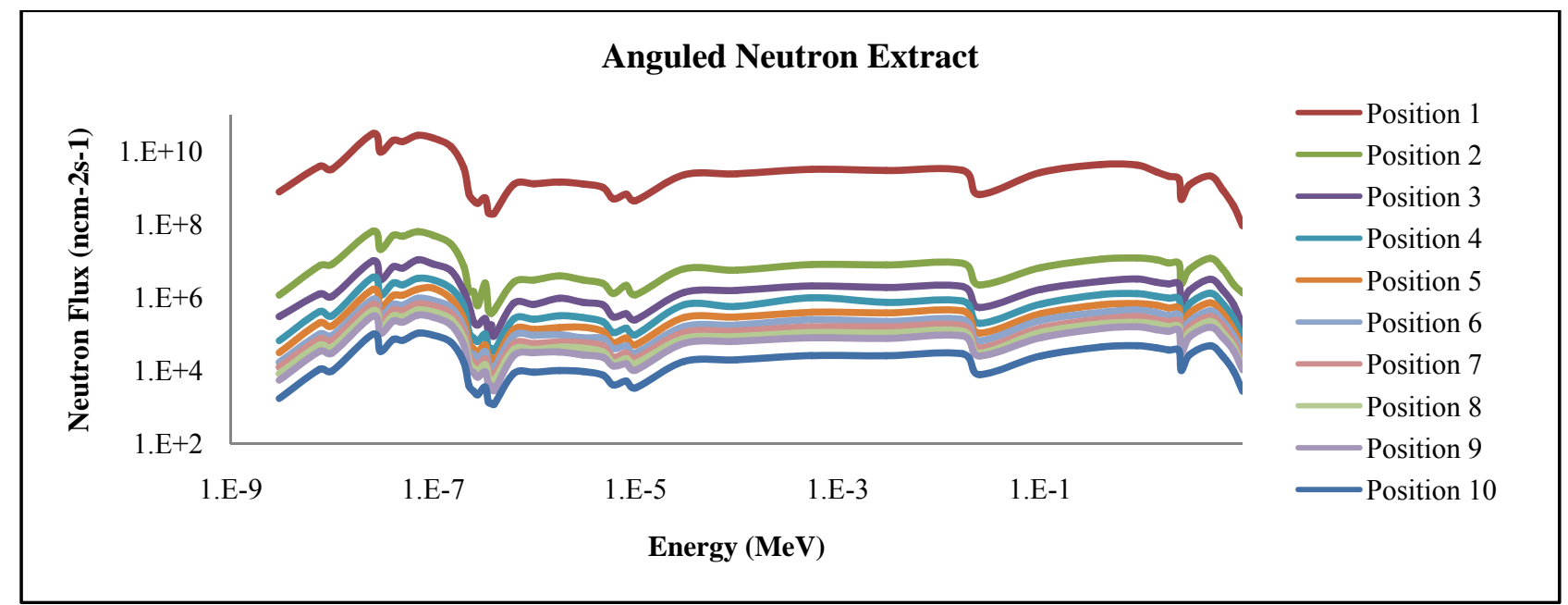

Fig. 8 Neutron flux behavior along the angled neutron extractor.

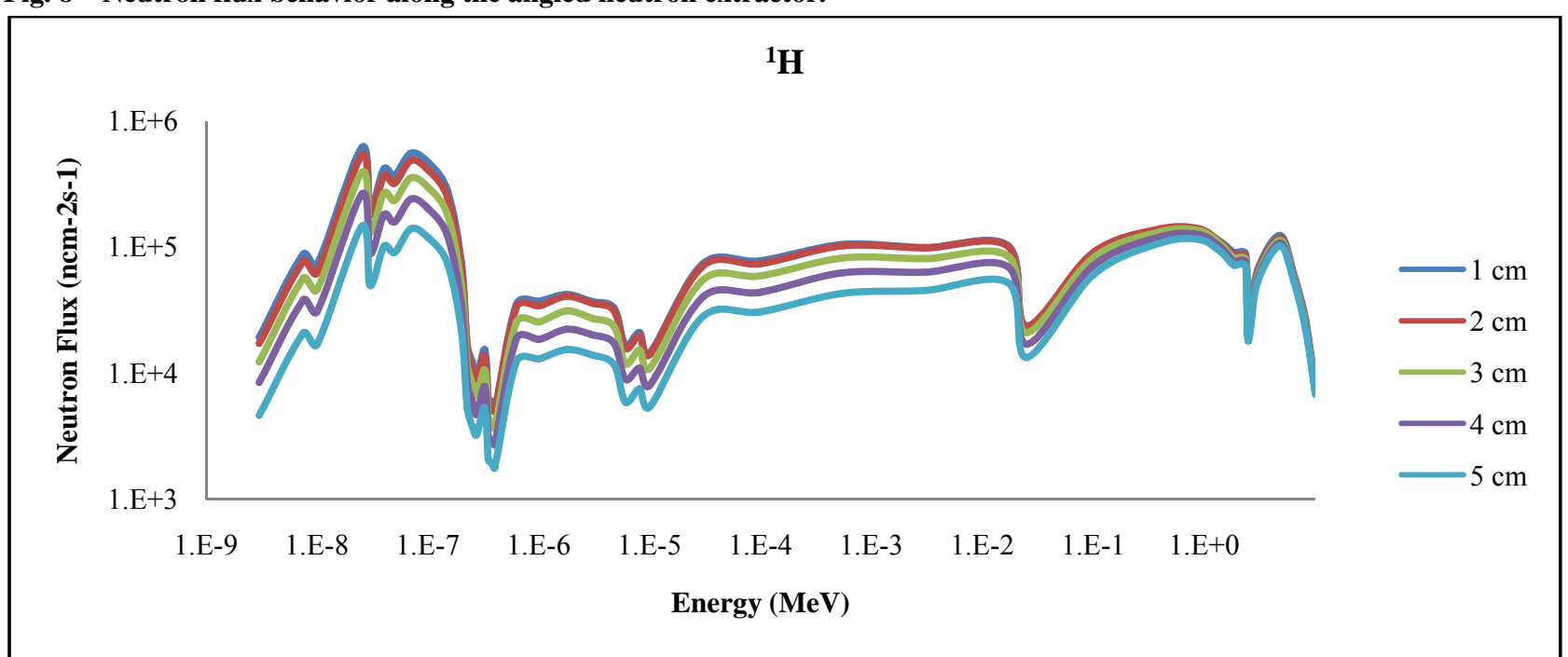

Fig. 9 Neutron flux behavior along ${ }^{1} \mathrm{H}$ sample.

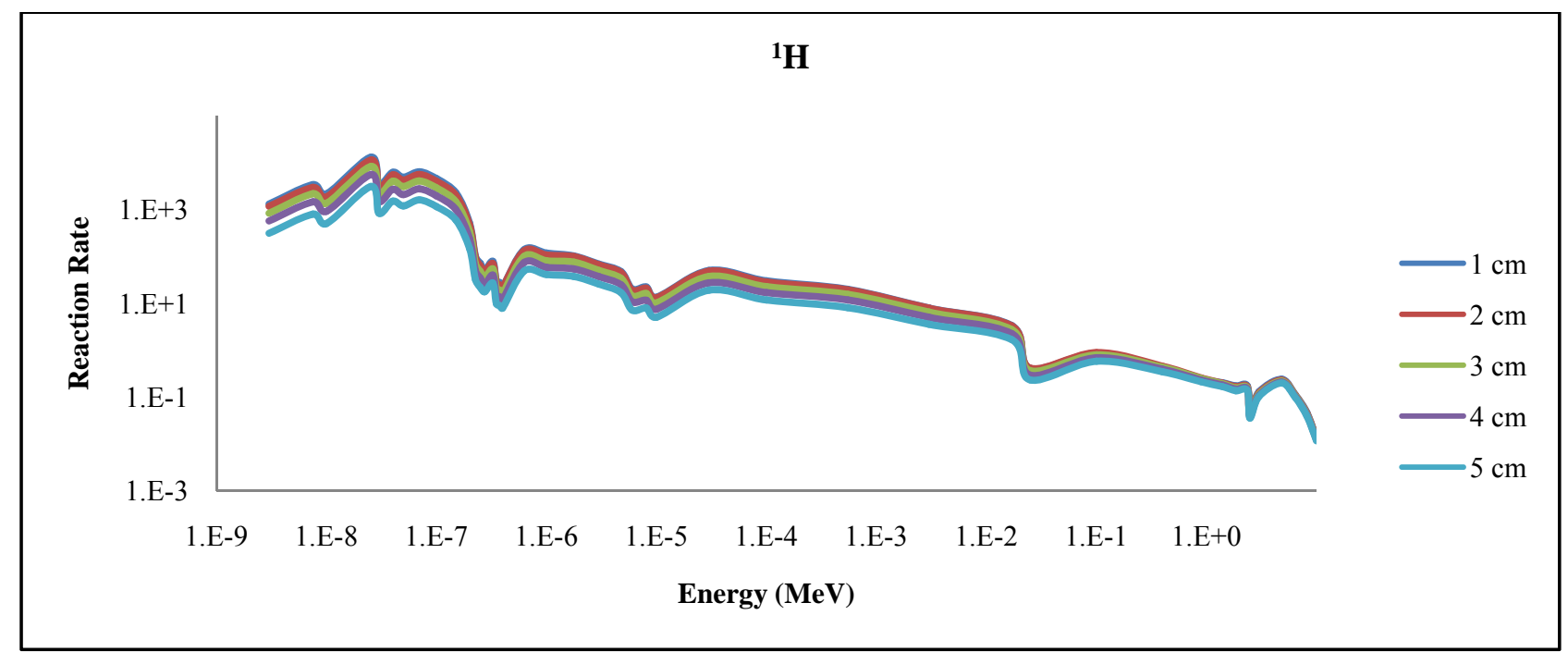

Fig. 10 Reaction rate along ${ }^{1} \mathrm{H}$ sample. 


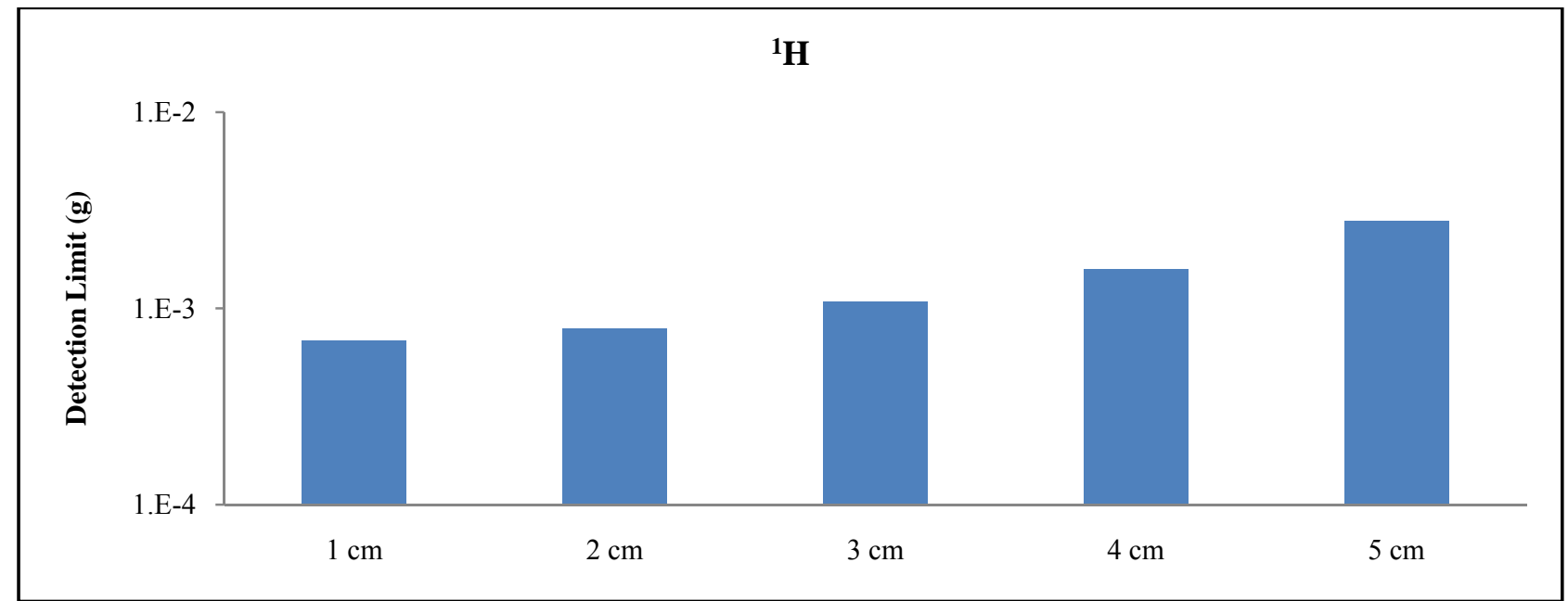

Fig. 11 Detection limit along ${ }^{1} \mathrm{H}$ sample.

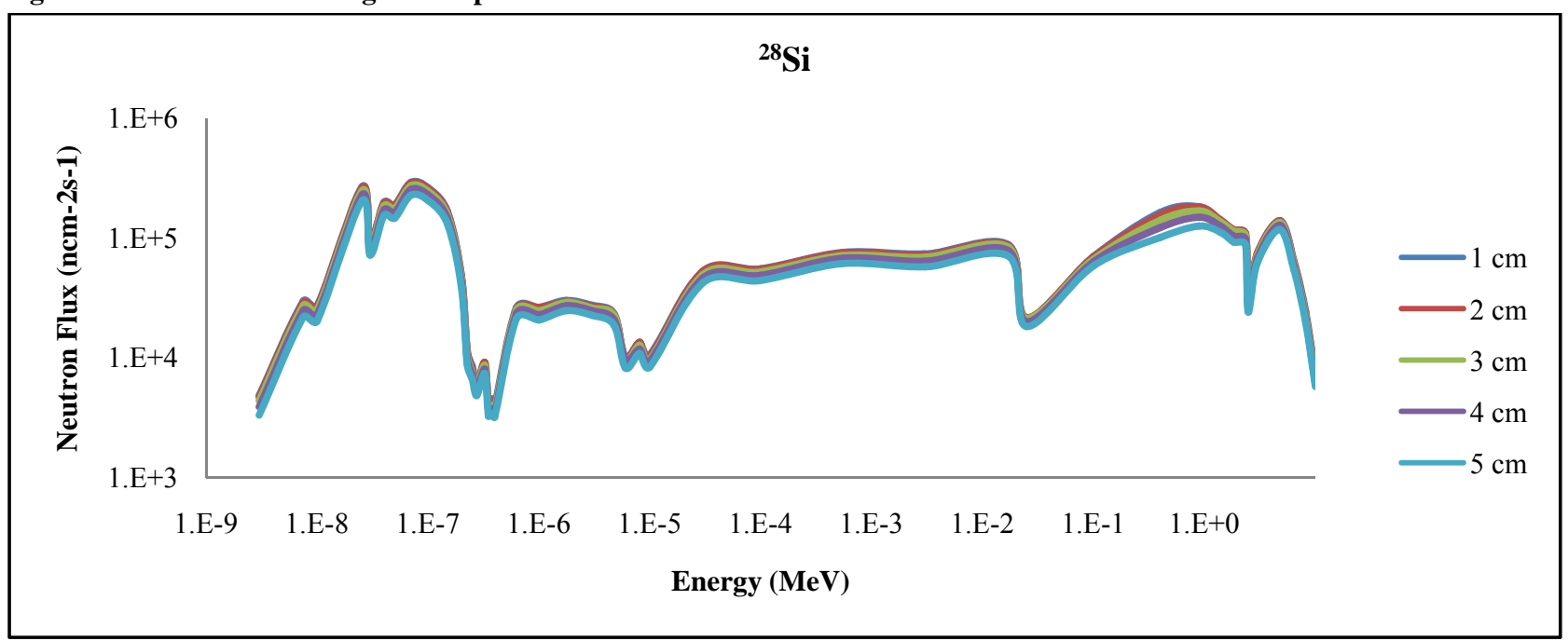

Fig. 12 Neutron flux behavior along ${ }^{28} \mathrm{Si}$ sample.

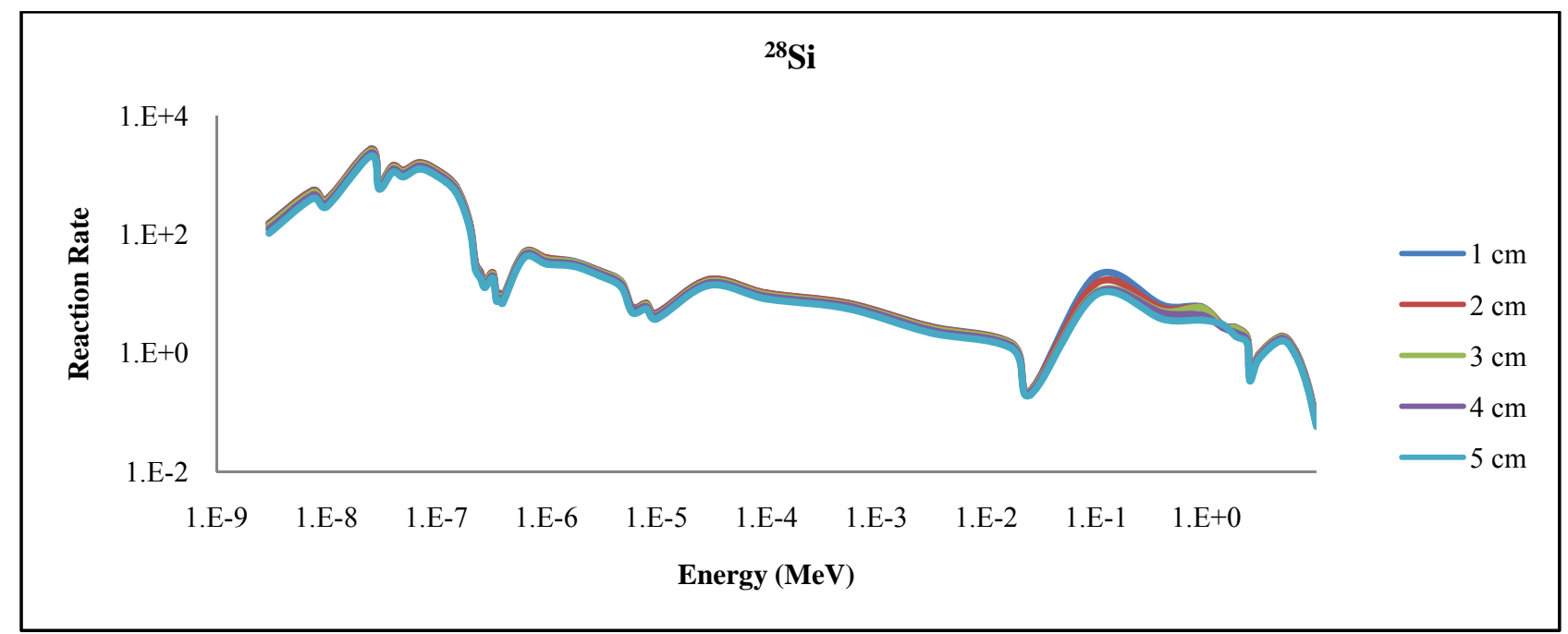

Fig. 13 Reaction rate along ${ }^{28} \mathrm{Si}$ sample. 


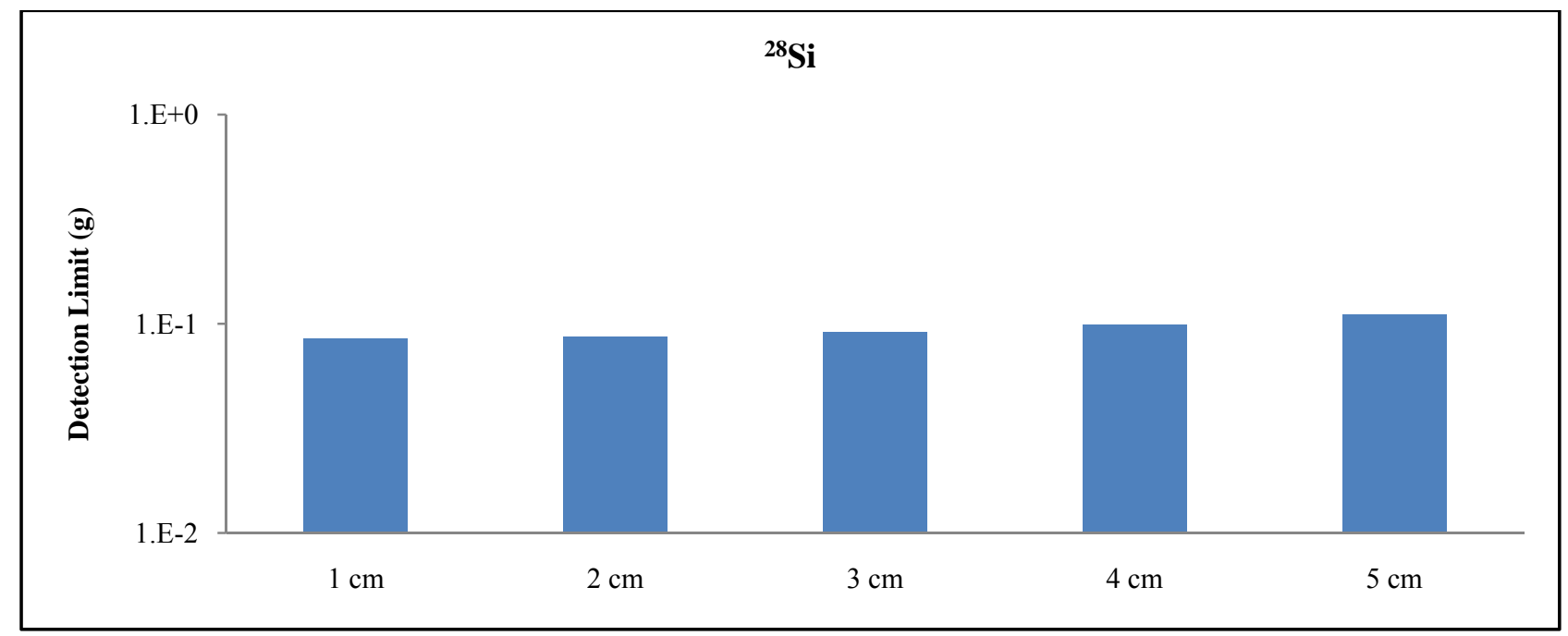

Fig. 14 Detection limit along ${ }^{1} \mathrm{H}$ sample.

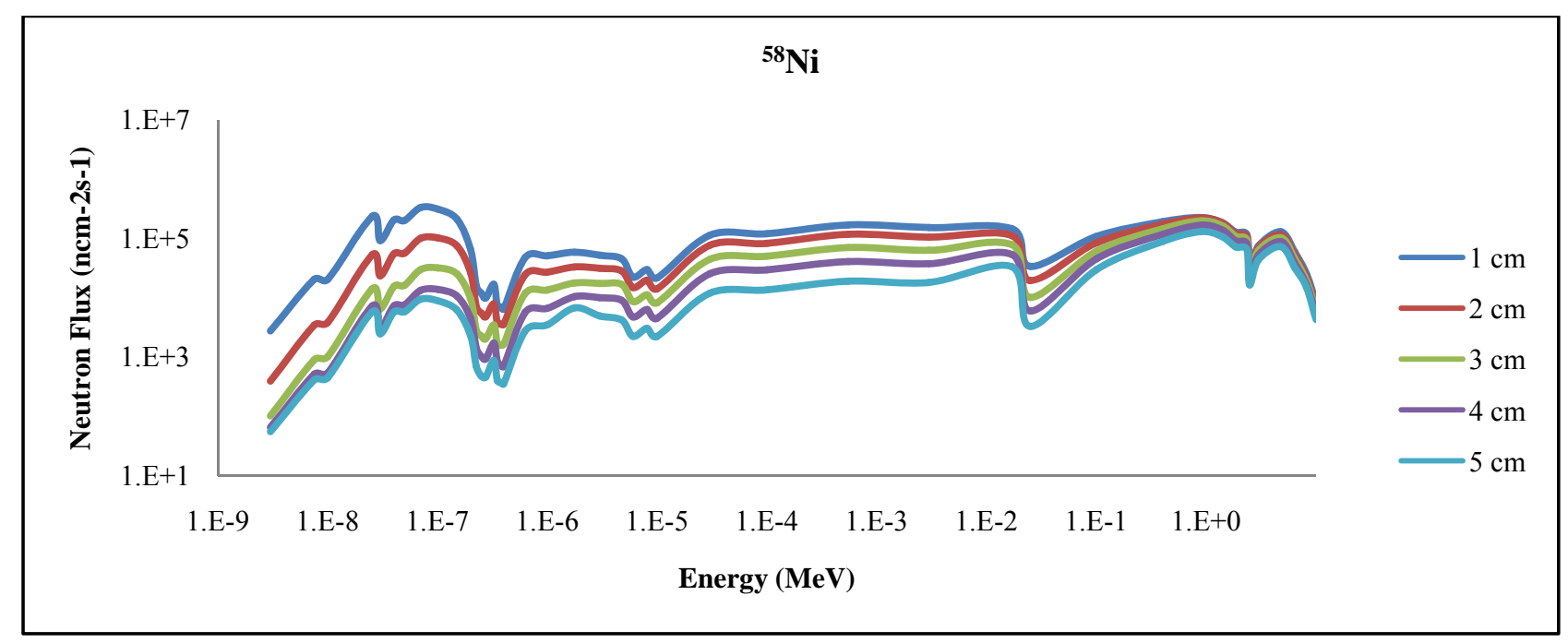

Fig. 15 Neutron flux behavior along ${ }^{58} \mathrm{Ni}$ sample.

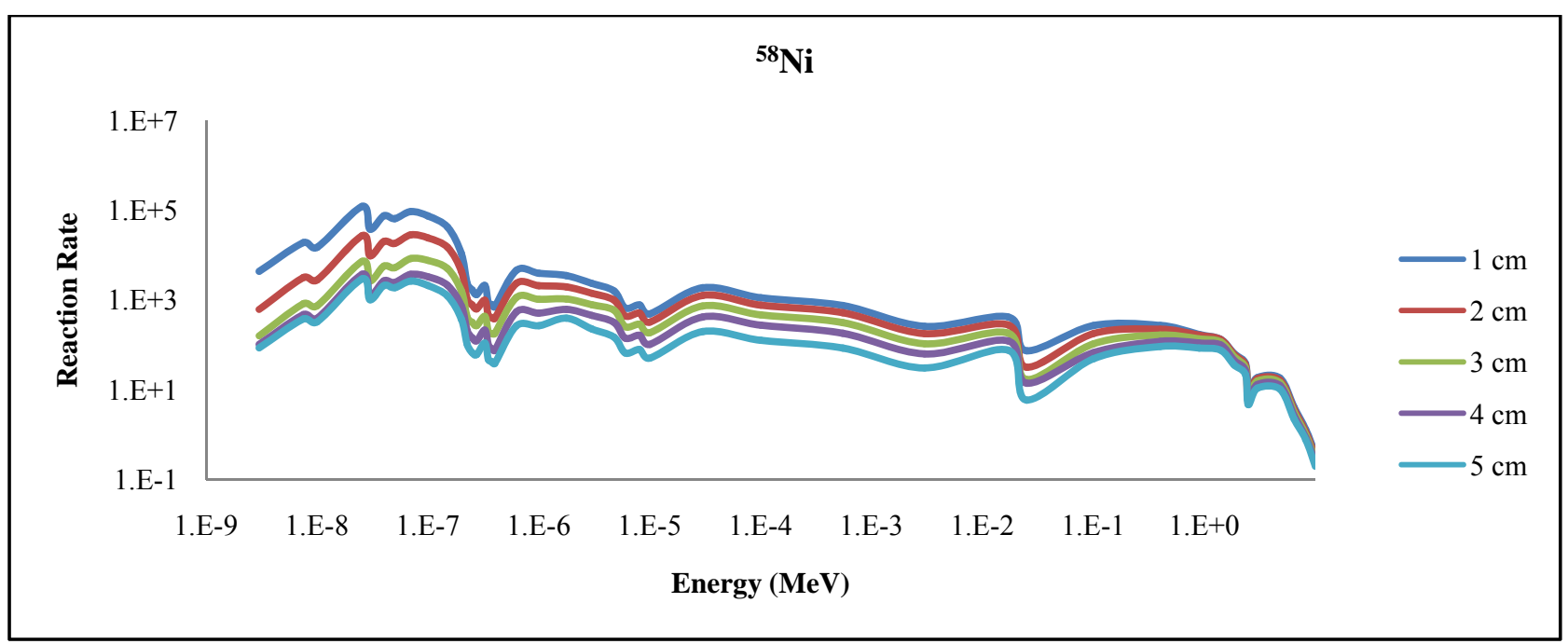

Fig. 16 Reaction rate along ${ }^{58} \mathrm{Ni}$ sample. 


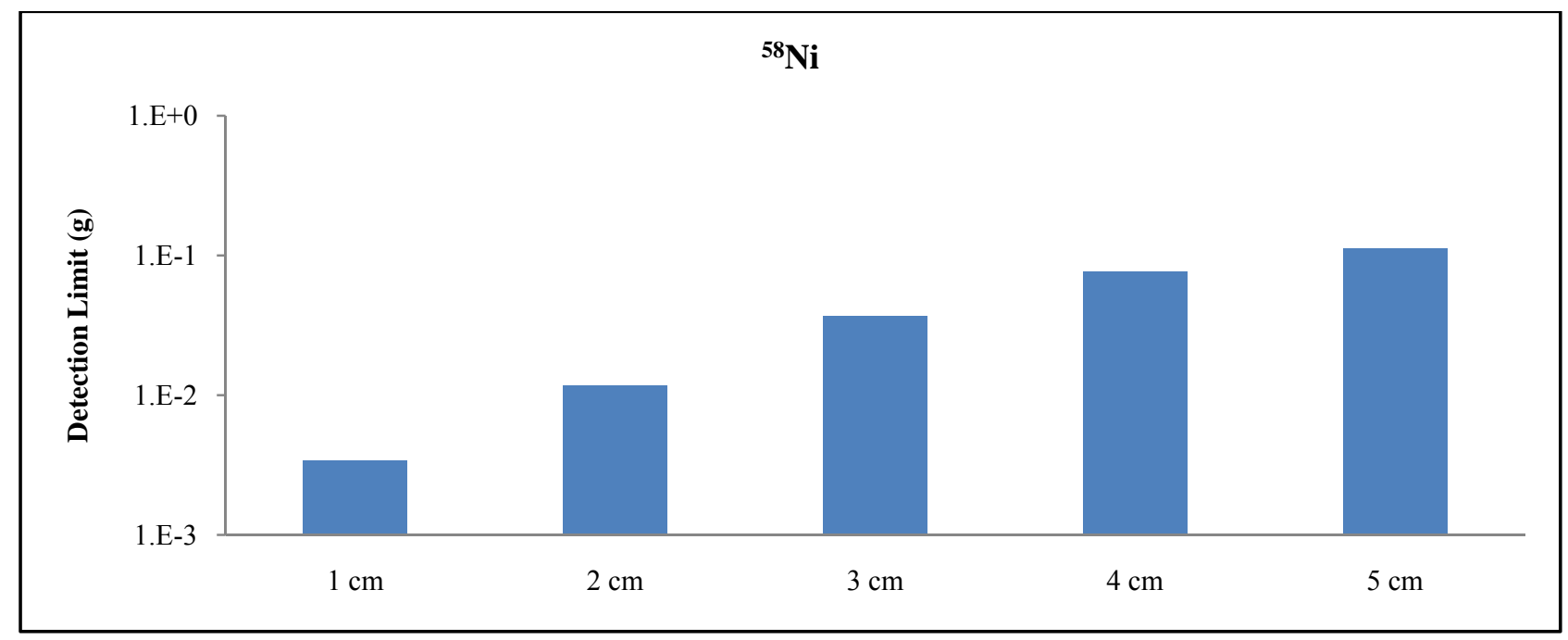

Fig. 17 Detection limit along ${ }^{58} \mathrm{Ni}$ sample.

section versus neutron spectrum obtained at IAEA has a highest capture cross section to a thermal neutron, Fig. 6.

As already mentioned, for the ${ }^{28} \mathrm{Si}$ and ${ }^{1} \mathrm{H}$ isotopes there was not a significant change in the neutron flux along the sample, but for the isotope ${ }^{58} \mathrm{Ni}$, there was a significant variation. Consequently, the reaction rate and the detection limit along the sample had a small variation for the ${ }^{1} \mathrm{H}$ and ${ }^{28} \mathrm{Si}$ isotopes, while for ${ }^{58} \mathrm{Ni}$ there had a significant variation, Figs. 9, 10, 12, 13 and 15,16 .

Thus, because the first layer of each isotope has the highest neutron flux, it was chosen as a reference to calculate and compare the detection limits obtained in this study with results of laboratories using the PGAA method. This comparison will be made in the next chapter.

For all calculations estimated in each isotope, the relative code error was $<5 \%$, which is acceptable [15-17].

\subsection{Comparison of Detection Limits}

Finally, based on the detection limits calculated in the first layers of each isotope was taken a comparison of the results obtained with MOLNAR [3] data, as shown in Figs. 18-20. In these Figs., from left to right side, Model 1 to Model 5.
The variation of the detection limit between Model 1 and Model 2 (calculated using estimates obtained in this study and some approaches in order to compare these models) was in the order of $10^{1}$ for ${ }^{1} \mathrm{H}$ and ${ }^{28} \mathrm{Si}$. The exact results of ${ }^{1} \mathrm{H}$ were $3 \times 10^{-7} \mathrm{~g}$ (Model 1) and $1.98 \times 10^{-6} \mathrm{~g}$ (Model 2) and for ${ }^{28} \mathrm{Si}$ were $8.43 \times 10^{-5} \mathrm{~g}$ (Model 1) and $2.46 \times 10^{-4} \mathrm{~g}$ (Model 2). Also, for ${ }^{58} \mathrm{Ni}$, the detection limit for Model 1 was in the same magnitude of the Model 2, $1.8 \times 10^{-6} \mathrm{~g}$ (Model 1) and $9.86 \times 10^{-6} \mathrm{~g}$ (Model 2).

The highest variation was for standard models (Model 1) related to the models with the parameters for the PGAA application at IPR-R1 reactor (Model 5), for all isotopes, the variation was in the order of $10^{3}$, ${ }^{1} \mathrm{H}$ of $3 \times 10^{-7} \mathrm{~g}$ (Model 1) to $3.43 \times 10^{-3} \mathrm{~g}$ (Model 5), ${ }^{28} \mathrm{Si}$ of $8.43 \times 10^{-5} \mathrm{~g}$ (Model 1) to $8.55 \times 10^{-2} \mathrm{~g}$ (Model 5) and ${ }^{58} \mathrm{Ni}$ of $8.01 \times 10^{-6} \mathrm{~g}$ (Model 1) to $3.43 \times 10^{-3} \mathrm{~g}$ (Model 5).

This variation of $10^{3}$ occurs because the example acquired in MOLNAR [3] (Model 1) has a neutron flux in the order of $10^{2} \mathrm{ncm}^{-2} \cdot \mathrm{s}^{-1}$, higher than the neutron flux in the IPR-R1 reactor (Model 5). Moreover, the time that the samples can be subjected to the neutron flux at Model 1 is $10^{5}$ seconds; while in Model 5 is $2.88 \times 10^{4}$ seconds.

The detection limit is the lowest amount of an isotope that can be identified in the sample, i.e., the 
lower limit detection has greater accuracy in the analysis. Thus, the greater neutron flux interacting

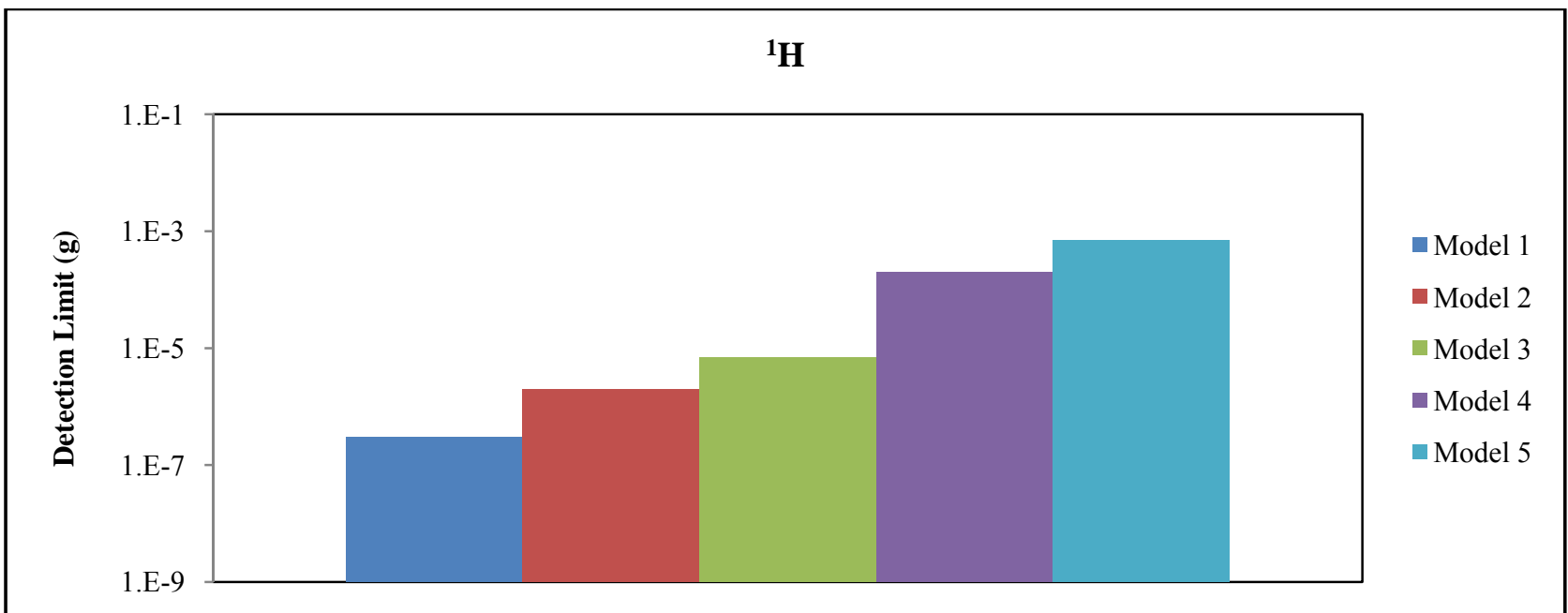

Fig. 18 Detection limit for ${ }^{1} \mathrm{H}$ sample.

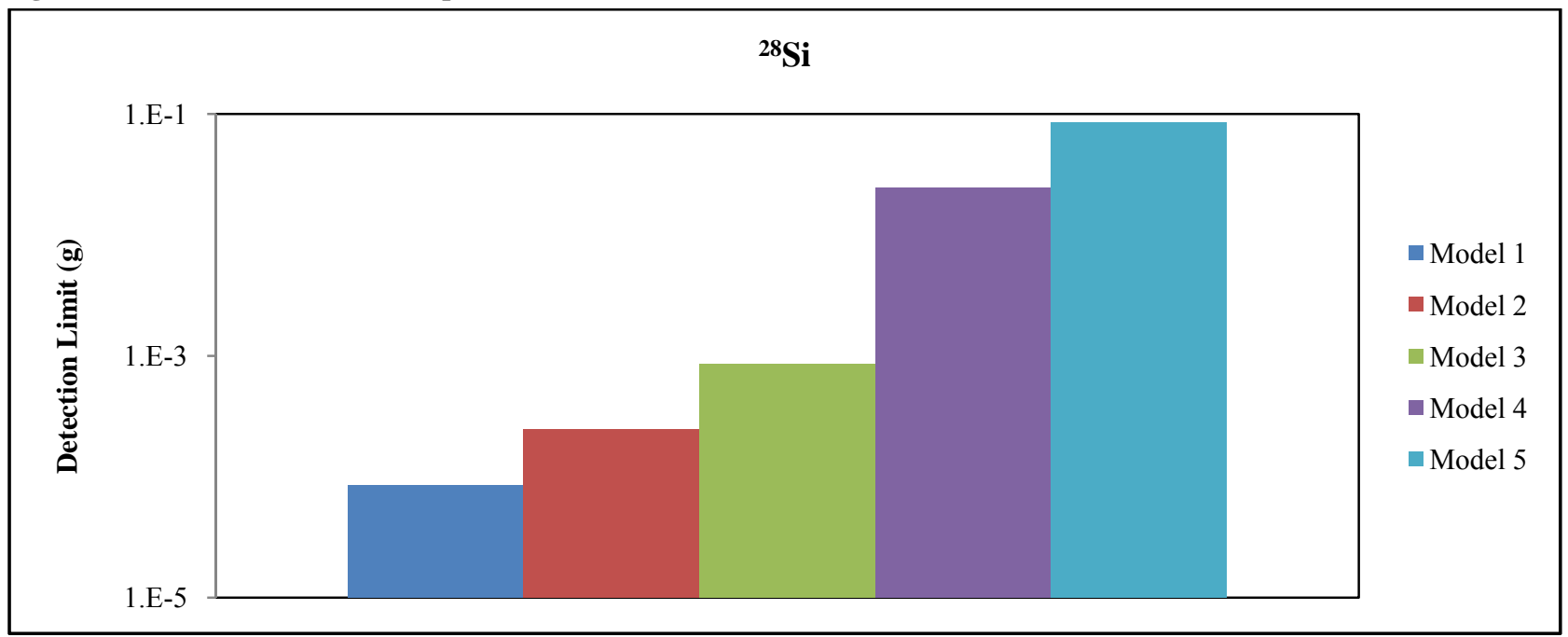

Fig. 19 Detection limit for ${ }^{28} \mathrm{Si}$ sample.



Fig. 20 Detection limit for ${ }^{58} \mathrm{Ni}$ sample. 
with the sample will have the higher probability of capture reaction rate in the isotope that will be analyzed.

As can be seen in Figs. 18-20, the lowest limit of detection obtained for the isotopes ${ }^{1} \mathrm{H},{ }^{28} \mathrm{Si}$ and ${ }^{58} \mathrm{Ni}$ were found in the Model 1, while for the Model 5 had the highest detection limits, this is due to the fact of Model 1 has the highest neutron flux and longer irradiation and Model 5 has the lowest of these parameters.

However, it is important to note that the lowest neutron flux found in the literature about PGAA was $10^{5} \mathrm{ncm}^{-2} \cdot \mathrm{s}^{-1}$. Thus, it can be concluded that it is possible to apply the PGAA method at IPR-R1 reactor with a lower accuracy in the Model 1.

For all reaction rate calculations, the relative error of the MCNP5 was lower than $1 \%$, which is acceptable.

\section{Conclusions}

Considering that the reactor IPR-R1 operates routinely for 8 hours, it was necessary to do the same evaluation in a neutron extractor with a larger diameter $(10 \mathrm{~cm})$ to increase the efficiency of the method. According to MOLNAR [3], a neutron beam of $5 \times$ $10^{5} \mathrm{ncm}^{-2} \cdot \mathrm{s}^{-1}$ would be enough to apply the PGAA method. Through the MCNP5 model developed in this paper with a neutron extractor of $10 \mathrm{~cm}$, making it possible to obtain a thermal neutron flux in a sample of $6 \times 10^{5} \mathrm{ncm}^{-2} \cdot \mathrm{s}^{-1}$ and total flux of $1.13 \times 10^{6}$ $\mathrm{ncm}^{-2} \cdot \mathrm{s}^{-1}$, concluding that is possible to apply the PGAA method at the IPR-R1 reactor. Above all, the calculations of detection limit in the three isotopes were possible to identify each isotope with an acceptable accuracy degree.

Furthermore, there are some possibilities to expand the PGAA application, such as: increasing the time that the sample is submitted to a neutron beam; operate the reactor at a power of $250 \mathrm{~kW}$; increase over more the neutron extractor diameter; adjust the sample at the closest position of the reactor, among others.

Finally, it is important to remark that this theoretical study proved that it is possible to establish the PGAA method at the IPR-R1, but it is also necessary to perform an experimental analysis to evaluate more accurately the results obtained in this study and, then, to confirm the possibility to establish this method.

\section{References}

[1] Ehrhardt, G. J., Ketring, A. R., and Ayers, L. M. 1998. "Reactor-Produced Radionuclides at the University of Missouri Research Reactor." Applied Radiation and Isotopes 49 (4): 295-7.

[2] Soete, de D., Gijbels, R., and Hoste, J. 1972. Neutron Activation Analysis. Interscience, Division of Wiley, New York.

[3] Molnar, G. L. 2004. Handbook of Prompt Gamma Activation Analysis with Neutron Beams. Ed. Kluwer Academic Publishers, the Netherlands.

[4] Kellner R., Mermet, J. M., Otto, M., Valcárcel, M., and Widmer, H. M. 2004. Analytical Chemistry. Ed. WILEY-VCH Verlag GmbH \& Co. KGaA.

[5] Tófani, P. C., and Paiano, M. C. 1989. Uses of a Small Research Reactor in Brazil. NuclebrÁS, Cdtn, Cnen/Cdtn-611, Belo Horizonte.

[6] Menezes, M. Â. B. C., Sabino, C. V. S., Franco, M. B., Kastner, G. F., and Montoya, R. E. H. 2003. " $k_{0}$-Instrumental Neutron Activation Establishment at CDTN, Brazil: A Successful Story.” J. Radioanal. Nucl. Chem. 257: 627-32.

[7] Menezes, M. A. B. C., and Jacimovic, R. 2006. "Optimised $\mathrm{k}_{0}$-instrumental Neutron Activation Method using the Triga Mark I IPR-R1 Reactor at CDTN/CNEN, Belo Horizonte, Brazil." Nuclear Instruments \& Methods in Physics Research. Section A, Accelerators, Spectrometers, Detectors and Associated Equipment 564: 707-15.

[8] Leal, A., Krambrock, K., Ribeiro, L., Menezes, M. A. B. C., Vermaercke, P., and Sneyers, L. 2007. "Study of Neutron Irradiation-induced Colors in Brazilian Topaz." Nuclear Instruments \& Methods in Physics Research. Section A, Accelerators, Spectrometers, Detectors and Associated Equipment (Print) v. 580: 423-6.

[9] Leal, A., Junior, A., Abrantes, F., Menezes, M. A. B. C., Ferraz, V., Cruz, T., Cardoso, V., and Deoliveira, M. 2006. "Production of the Radioactive Antitumoral Cisplatin." Applied Radiation and Isotopes, Holanda 64: 178-81. 
[10] Paul, R. L., and Lindstrom, R. M. 2000. "Prompt Gamma-Ray Activation Analysis Fundamentals and Applications." Journal of Radioanalytical and Nuclear Chemistry 181-9.

[11] Naqvi, A. A., Nagadi, M. M., Khateeb-Ur-Rehman, Maslehuddin, M., and Kidwai, S. 2003. "Monte Carlo Simulations for Design of the Kfupm Pgnaa Facility." Radiation Physics and Chemistry 66: 89-98.

[12] Guerra, B. T., Jacimovic, R., Menezes, M. A. B. C., and Leal, A. S. 2013. "Proposed Design for the PGAA Facility at the Triga IPR-R1 Research Reactor." Journal Springer Plus 2 (597): 10.

[13] Guerra, B. T., Leal, A. S., Grynberg, S. E., and Menezes, M. A. B. C. 2013. "The Neutron and Gamma-ray dose Characterization using the Monte Carlo Method to Study the Feasibility of the Prompt Gamma Activation Analysis Technique at IPR-R1 TRIGA Reactor in Brazil." INAC2013 (International Nuclear Atlantic Conference 2013).

[14] Guerra, B. T., Leal, A. S., Pereira, C., and Menezes, M. A. B. C. 2015. "Analysis of Neutron Flux Distribution using the Monte Carlo Method for the Feasibility Study of the Prompt Gamma Activation Analysis Technique at the IPR-R1 TRIGA Reactor.” INAC2015 (International Nuclear Atlantic Conference 2015). São Paulo.

[15] SalomÉ, J. A. D., Guerra, B. T., Pereira, C., Menezes, M. A. B. C., Silva, C. A. M., Dalle, H. M., and Pereira, C. 2014. "Evaluation of the Thermal Neutron Flux in Samples of Al-Au Alloy Irradiated in the Carrousel
Channels of the Triga Mark I IPR-R1 Reactor Using MCNP Code." Nuclear Engineering and Design 273: 576-83.

[16] Silva, C. A. M., Pereira, C., Guerra, B. T., Veloso, M. A. F., Costa, A. L., Dalle, H. M., and Menezes, M. Â. B. C. 2011. "MCNP5 Modelling of the IPR-R1 Triga Reactor for Criticality Calculation and Reactivity Determination." Nuclear Engineering and Design 241: 4889-993.

[17] Silva, C. A. M., SalomÉ, J. A. D., Guerra, B. T., Pereira, C., Costa, A. L., Veloso, M. A. F., Menezes, M. Â. B. C., and Dalle, H. M. 2014. "Sensitivity Analysis of the TRIGA IPR-R1 Reactor Models Using the MCNP Code." International Journal of Nuclear Energy Volume 2014 (2014), Article ID 793934, 9 pages

[18] Briesmeister, J. F. 2000. "MCNP-A General Monte Carlo N-Particle Transport Code, Version 4C." Los Alamos National Laboratory, Report LA-13709-M.

[19] Briesmeister, J. F. 2003. "MCNP-A General Monte Carlo N-Particle Transport Code, Version 5." Los Alamos National Laboratory.

[20] Brookes, C. J., Betteley, I. G., and Loxton, S. M. 1979. Fundamentals of Mathematics and Statistics. Birmingham, John Wiley \& Sons.

[21] Centro Nacional DE Processamento DE ALTO DESEMPENHO PARA MINAS GERAIS CENAPAD-MG, Brasil, www.cenapad.ufmg.br/, access: 4/2016.

[22] https://www-nds.iaea.org/exfor/exfor.htm, access: $7 / 2016$. 